\title{
Effects of pre and post-veraison water deficit on Vermentino cluster microclimate and berry composition
}

\author{
Ana Fernandes de Oliveira ${ }^{*}$, Luca Mercenaro, Mario Azzena, and Giovanni Nieddu \\ Department of Agriculture, University of Sassari, Viale Italia 39, 07100 Sassari (Italy)
}

\begin{abstract}
The influence of light and thermal microclimate on berry quality of a Vermentino vineyard, managed with deficit irrigation strategies in north-western Sardinia, was analyzed. Two water deficit, pre- (ED) and post-veraison (LD), an irrigation (IC) and a non-irrigation (NC) control treatments were compared during berry development. Grapevine performances were evaluated by analyzing leaf gas exchange, source-sink balance, light and thermal microclimate effects on berry composition. Early and/or late deficit irrigation following a mild to moderate water stress threshold enabled high leaf physiological performances. Though with high stomatal conductance sensitivity to water deficit and anisohydric behavior, this variety exhibited high assimilation rate and quick recovery capacity after enduring moderate and severe water stress. All treatments achieved satisfactory sugar and acidic levels. Berry phenols were higher in LD due to lower canopy coverage and better light conditions compared to IC. Up to mid-ripening, cluster exposure to elevated temperatures negatively influenced phenolic accumulation, mostly in $\mathrm{NC}$ and to a lower extent in ED. In the last ripening weeks, total phenols was majorly influenced by light interception.
\end{abstract}

\section{Introduction}

Water deficit affects berry composition in red and white grapes [1-3]. Concentration and composition of colour and flavour compounds such as phenolics may be affected. By decreasing berry weight with post-veraison water deficit, a higher proportion of skin and seeds, containing extractable phenolics, can be obtained [3-6]. Additionally, water stress-induced changes in cluster microclimate may lead to different berry phenolic content and partitioning [5-7]. Relationships between plant water status and accumulation of different phenolic groups in growing berries are not fully understood $[8,9]$. In this work, we applied deficit irrigation strategies in a white grape variety and imposed mild to moderate water stress using a stem water potential $(\Psi \mathrm{s})$ threshold [10] above which vines were not re-watered. Pre and postveraison irrigation treatments were established from fruit set until harvest. Variety performance under water stress was evaluated by analysing leaf gas exchange, sourcesink balance, light and thermal microclimate effects on berry.

\section{Material and Methods}

\subsection{Experimental site and irrigation strategies}

The study was conducted on Vitis vinifera L. cv. Vermentino, a white wine grape cultivated in western
Mediterranean areas. The trial was carried out in 2011 on a four year-old commercial vineyard located in Alghero, Sardinia, Italy. The vines, grafted onto 1103 P rootstock, were planted on a sandy-clay-loam soil, in north-south oriented rows, spaced $2.5 \mathrm{~m} \times 1 \mathrm{~m}$ and cane-pruned to a single Guyot of six nodes per cane plus a two-bud renewal spur. Irrigation was scheduled weekly when $\Psi$ s fell below a mild water stress threshold [10]. Surface drip irrigation ( $4 \mathrm{~L} \mathrm{~h}^{-1}$ emitters) was used. Following a randomized design of 3 blocks with 3 vine rows each, 4 treatments were set: Early deficit (ED), for which vines were irrigated from fruit-set to veraison when $\Psi \mathrm{s}$ decreased below $-0.8 \mathrm{MPa}$; Late deficit (LD), supplying water from veraison until harvest, according to the same threshold; irrigated control (IC) in which $\Psi$ s was kept around $-0.8 \mathrm{MPa}$ during fruit development and ripening; and non-irrigated control (NC). By the end of ripening, water was applied also to NC plants (DOY 241), when $\Psi$ s fell to $-1.8 \mathrm{MPa}$, to prevent the risk of compromising plant survival. Irrigation was applied 5 times in ED, 4 in LD, 9 in IC and once in NC, for a total amount of 773, 587, 1360 and $160 \mathrm{~m}^{3} \mathrm{ha}^{-1}$, respectively. Precipitation from May to September were about $1370 \mathrm{~m}^{3} \mathrm{ha}^{-1}$ [11].

\subsection{Physiological status, growth, productivity}

Midday $\Psi$ s was measured with a pump-up pressure chamber (PMS Instruments, USA), on adult leaves covered with aluminium foil-coated plastic bags 1 hour prior to the measurement. Net assimilation (An, $\mu \mathrm{mol}$ $\mathrm{CO}_{2} \mathrm{~m}^{-2} \mathrm{~s}^{-1}$ ), stomatal conductance (gs, mmol m $\mathrm{m}^{-2} \mathrm{~s}^{-1}$ ),

Corresponding author: $\underline{\text { acortez@, uniss.it }}$ 
transpiration rate $\left(\mathrm{E}, \mathrm{mmol} \mathrm{H}_{2} \mathrm{O} \mathrm{m}^{-2} \mathrm{~s}^{-1}\right)$, intrinsic water use efficiency (WUEi, $\mu \mathrm{mol} \mathrm{mmol}^{-1}$ ) and leaf temperature $\left(\mathrm{T}_{\text {leaf }},{ }^{\circ} \mathrm{C}\right)$ were evaluated, on fully expanded, well-exposed leaves, at midmorning, using a portable LCA Ciras-1 (PP Systems, USA). Measurements were taken at ambient $\mathrm{CO}_{2}$ reference concentration $\left(390 \mu \mathrm{mol} \mathrm{mol}{ }^{-1}\right)$ and ambient saturating photosynthetic photon flux density (1700 and $2300 \mu \mathrm{mol}$ $\mathrm{m}^{-2} \mathrm{~s}^{-1}$ during the season).

Primary and lateral leaf area were estimated when berries were pea sized and at mid-ripening (stages 7.5 and 8.5 BBCH scale), using empirical models [12]. Yield components and pruning weight per vine were recorded. Leaf area (LA) (at 8.5 $\mathrm{BBCH}$ stage) to yield ratio and Ravaz index were determined. Irrigation water productivity (IWP) was expressed as $\mathrm{kg}$ of clusters per $\mathrm{m}^{3}$ of water supplied.

\subsection{Cluster microclimate and berry composition}

Cluster light interception was appraised based on PAR intensity measurements through the fruit zone, at midday, under clear sky conditions, using a ceptometer (Sunscan SS1, Delta-T Devices, UK). PAR transversal profiles were collected across the canopy and a total PAR sensor (BF3, Delta T Devices, UK) was used to record reference PAR, incident at the top of the canopy. Berry temperature was monitored every $10 \mathrm{~min}$ with fine-wire thermistors (GMR Strumenti, IT) connected to data-loggers (Zeta-tec, UK). Thermal time was computed using normal heat hours (NHH) [13]. The number of hours with elevated temperatures $\left(>35^{\circ} \mathrm{C}\right.$, HT35) were calculated for the duration of ripening. Berry samples were sampled weekly from veraison to harvest. Berry fresh mass, total soluble solids (TSS), $\mathrm{pH}$, titratable acidity, malic and tartaric acid were determined [14]. Total phenols were analysed spectrophotometrically [15]. Sugar loading was calculated multiplying berry weight by TSS.

\subsection{Statistical analysis}

Analysis of variance (ANOVA) and least significant difference (LSD) tests were performed to compare means and detect significant differences among treatments at $95 \%$ confidence level. Main and interactive effects of irrigation treatment and cluster exposure on HT35 were investigated by two-way ANOVA. Principal component analysis (PCA) was used to observe common variation and summarize relationships among berry skin phenol content, HT35 and LA among irrigation treatments.

\section{Results}

\subsection{Meteorological conditions}

The thermal conditions during the season were close to the average values of the period 1980-2010. However, climatic water budget (Precipitation (PP) - Potential

Evapotranspiration (ETP)) reached a cumulative deficit of as much as $-590 \mathrm{~mm}[11]$.

\subsection{Physiological status, growth, productivity}

The patterns of $\Psi$ s reflected different plant water status among the treatments along the season (Fig.1). Until veraison (DOY 223), a decreasing trend of $\Psi$ s was observed in every treatment, as the evapo-transpirative demand increased, and $\mathrm{ED}$ and $\mathrm{NC}$ plants registered lower $\Psi_{\mathrm{s}}$. However, the differences among treatments decreased at BBCH stage 7.9 (DOY 209), due to rainfall events affecting all treatments equally. In IC plants, $\Psi_{\mathrm{s}}$ varied close to $-0.8 \mathrm{MPa}$. NC and ED plants experienced severe water deficit at veraison and in the first week of ripening (DOY 215-223). At this stage, both IC and LD reached moderate stress.
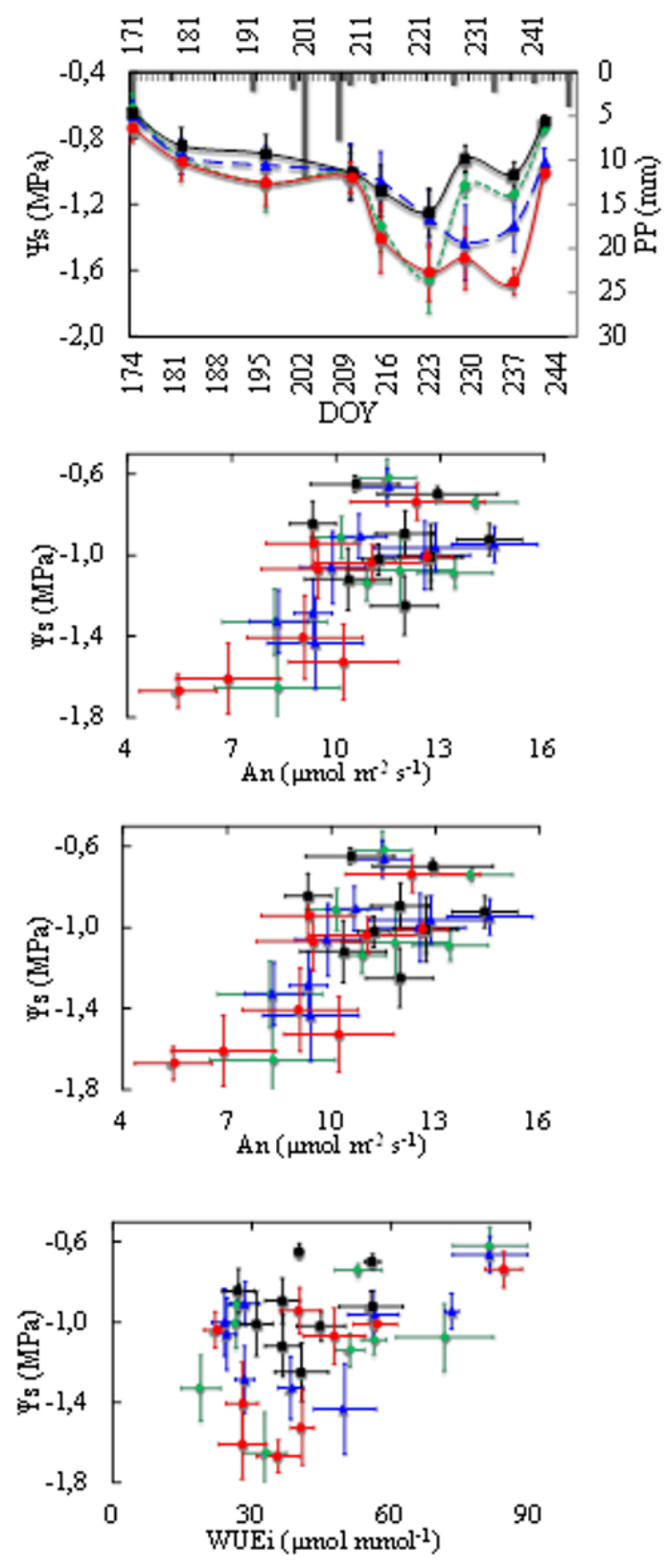


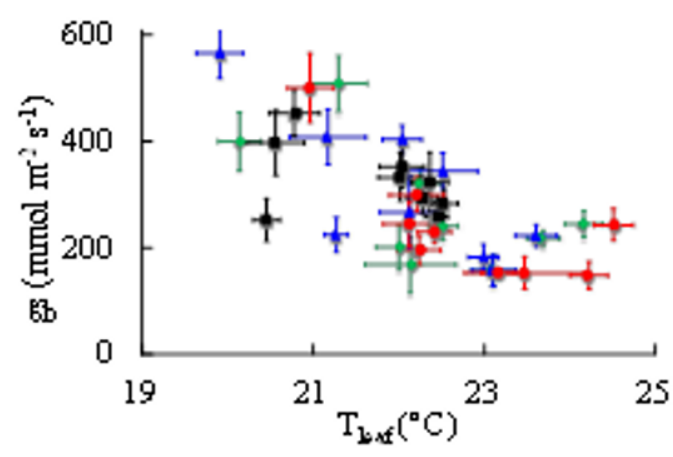

Fig.1. Season $\Psi$ s and PP (A); relationships between $\Psi$ s and An (B), Is and WUEi (C), and between gs and $\mathrm{T}_{\text {leaf }}(\mathrm{D})$ in the treatments $(\mathrm{ONC}, \triangle \mathrm{ED}, \mathbf{\square} \mathrm{IC}$ and $\boldsymbol{\Delta} \mathrm{LD})$. Mean $(\mathrm{n}=9) \pm \mathrm{SE}$.

After the first re-watering, ED plants were able to rapidly recover to a mild water stress status, while $\Psi$ s continued to decrease in $\mathrm{LD}$ and $\mathrm{NC}$, remaining respectively at moderate and severe water stress values, at 2 and 3 weeks after veraison. Meanwhile, ED plants recovered to $\Psi \mathrm{s}$ values similar to those of IC plants. Finally, after the single irrigation event, 4 weeks after veraison, even NC plants were able to recover to mild water status, even if these plants had been subjected to severe water stress.

The NC and ED leaves exhibited slightly lower net assimilation, stomatal conductance and transpiration rates before veraison, but only stomatal conductance values were statistically lower than that of IC. By the end of veraison, $\mathrm{NC}$ and ED plants showed the lowest net assimilation, stomatal conductance and transpiration. In $\mathrm{NC}$, net assimilation decreased continuously yet, by the end of ripening, these plants were still able to reach photosynthetic rates found in IC after irrigation. The seasonal trends of daily maximum photosynthetic rate varied with plant water status in NC, ED and LD. Maximum net photosynthetic rate responded similarly in ED and LD to the variation of $\Psi$ s, increasing whenever mild water deficit was reset. Despite the milder water status of IC, net assimilation did not increase above the values reached in ED and LD. Daily maximum stomatal conductance ranged between similar values in ED, LD and NC. However, in IC, stomatal aperture did not reach higher maximum values than the other treatments. As far as leaf temperature is concerned, sharp correlation was observed with stomatal conductance in less irrigated treatments. As plant water status decreased, stomatal control became tighter and leaf temperature increased, reaching the highest values in NC and ED. The highest intrinsic water use efficiency was observed in NC, ED and LD when mild water stress was perceived. Conversely, low intrinsic water use efficiency was recorded regardless of $\Psi$ s.

When berries reached the pea sized stage, the differences among treatments in total leaf area per vine were not statistically significant (Fig.2); at ripening, total leaf area was significantly lower in NC. Additionally, significant lateral shoot growth occurred in IC but not in ED and LD plants.
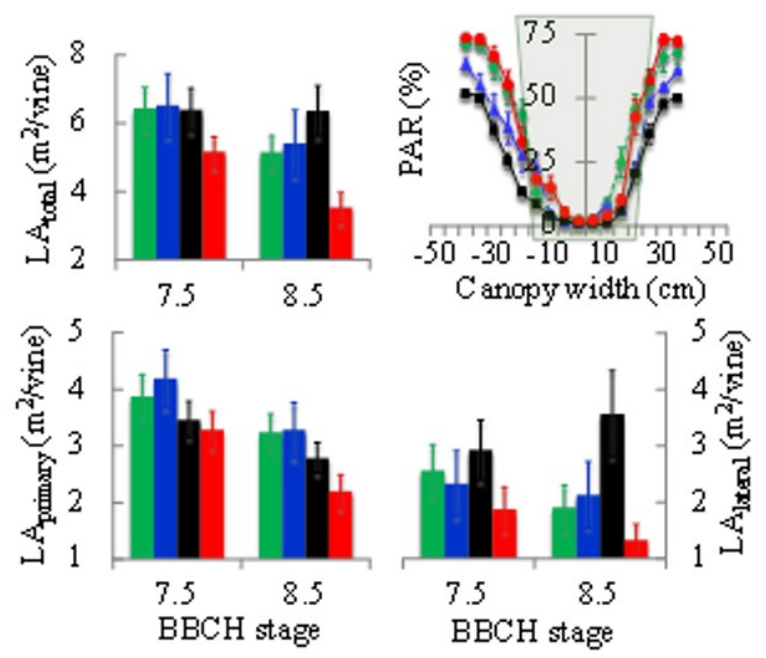

Fig.2. Total, primary and lateral leaf area (LA) for pea sized berries (7.5) and at mid-ripening (8.5) according to the $\mathrm{BBCH}$ scale, and midday PAR in the fruit zone at veraison (8.1), in the treatments $(\bigcirc \mathrm{NC}, \diamond \mathrm{ED}, \boldsymbol{\square} \mathrm{IC}$ and $\boldsymbol{\Delta} \mathrm{LD})$. Mean $(\mathrm{n}=12) \pm$ SE.

As compared to IC, ED and LD strategies resulted in increased irrigation water productivity while maintaining similar yield (Table 1). Though notable water saving was achieved with $\mathrm{NC}$, it resulted in a significantly lower yield than that of IC plants, mainly due to lower cluster weight. Both leaf area/yield ratio and pruning weight did not differ significantly among treatments, though IC plants presented slightly higher cane weight (1.11 $\mathrm{kg} / \mathrm{vine})$ as compared to $\mathrm{NC}(0.75 \mathrm{~kg} / \mathrm{vine})$.

Table 1. Yield components, leaf area/yield, pruning weight, Ravaz index, irrigation water productivity and berry composition at harvest. Different letters indicate significant difference at $\mathrm{P} \leq 0.05$ and $n$ refers to non-significant differences among treatments.

\begin{tabular}{|l|c|c|c|c|c|}
\hline & \multicolumn{3}{|c|}{ Treatment } & \multirow{2}{*}{$\boldsymbol{P}$} \\
\hline & ED & LD & IC & NC & \\
\hline Yield $(\mathrm{kg} /$ vine $)$ & $2.52 \mathrm{ab}$ & $2.33 \mathrm{ab}$ & $3.25 \mathrm{a}$ & $2.14 \mathrm{~b}$ & $\leq 0.05$ \\
\hline Cluster number & 11 & 10 & 11 & 11 & $\mathrm{~ns}$ \\
\hline Cluster weight $(\mathrm{kg})$ & $0.234 \mathrm{~b}$ & $0.225 \mathrm{~b}$ & $0.293 \mathrm{a}$ & $0.197 \mathrm{~b}$ & $\leq 0.05$ \\
\hline Leaf area/yield $\left(\mathrm{m}^{2} \mathrm{~kg}^{-1}\right)$ & 2.24 & 2.34 & 1.97 & 1.92 & $\mathrm{~ns}$ \\
\hline Pruning mass $\left(\mathrm{kg} / \mathrm{vine}^{\prime}\right)$ & 0.84 & 0.87 & 1.11 & 0.75 & $\mathrm{~ns}$ \\
\hline Ravaz Index & 2.95 & 2.67 & 2.93 & 2.55 & $\mathrm{~ns}$ \\
\hline IWP $\left(\mathrm{g} \mathrm{L}^{-1}\right)$ & $12.9 \mathrm{~b}$ & $15.8 \mathrm{~b}$ & $9.6 \mathrm{c}$ & $47.9 \mathrm{a}$ & $\leq 0.05$ \\
\hline Berry fresh weight $(\mathrm{g})$ & 2.69 & 2.88 & 2.96 & 2.78 & $\mathrm{~ns}$ \\
\hline TSS $\left({ }^{\circ}\right.$ Brix $)$ & 25.6 & 25.4 & 25.1 & 26.1 & $\mathrm{~ns}$ \\
\hline Sugar/berry & 0.82 & 0.7 & 0.72 & 0.67 & $\mathrm{~ns}$ \\
\hline pH & 3.78 & 3.68 & 3.63 & 3.61 & $\mathrm{~ns}$ \\
\hline Titratable acidity $(\mathrm{g} / \mathrm{L})$ & 4.29 & 4.25 & 4.52 & 4.47 & $\mathrm{~ns}$ \\
\hline Malic acid $(\mathrm{g} / \mathrm{L})$ & 0.82 & 0.79 & 1.02 & 0.77 & $\mathrm{~ns}$ \\
\hline Tartaric acid $(\mathrm{g} / \mathrm{L})$ & 2.99 & 2.82 & 3.26 & 3.18 & $\mathrm{~ns}$ \\
\hline
\end{tabular}

\subsection{Cluster microclimate and berry quality}

Midday PAR intercepted by the clusters, at veraison, was significantly lower in external layers of IC canopies compared to NC and ED (Fig.2, Table 2). Sunlight interception in the external LD clusters was also lower than in NC and ED but slightly higher than in IC. 
Table 2. Significance of the differences among treatments concerning midday PAR interception in the fruit zone at veraison (DOY 203). Different letters indicate significant difference and ns refers to non-significant differences

\begin{tabular}{|c|c|c|c|c|c|c|}
\hline \multirow{2}{*}{ Treatment } & \multicolumn{6}{|c|}{ Canopy width (cm) from the central layer } \\
\cline { 2 - 7 } & $\mathbf{- 4 0}$ & $\mathbf{- 3 5}$ & $\mathbf{- 1 0}$ & $\mathbf{1 0}$ & $\mathbf{3 5}$ & $\mathbf{4 0}$ \\
\hline $\mathrm{NC}$ & $\mathrm{a}$ & $\mathrm{A}$ & $\mathrm{ns}$ & $\mathrm{ns}$ & $\mathrm{a}$ & $\mathrm{a}$ \\
\hline $\mathrm{ED}$ & $\mathrm{A}$ & $\mathrm{A}$ & $\mathrm{ns}$ & $\mathrm{ns}$ & $\mathrm{ab}$ & $\mathrm{ab}$ \\
\hline $\mathrm{IC}$ & $\mathrm{B}$ & $\mathrm{B}$ & $\mathrm{ns}$ & $\mathrm{ns}$ & $\mathrm{b}$ & $\mathrm{c}$ \\
\hline $\mathrm{LD}$ & $\mathrm{A}$ & $\mathrm{b}$ & $\mathrm{ns}$ & $\mathrm{ns}$ & $\mathrm{ab}$ & $\mathrm{b}$ \\
\hline$P$-value & 0.002 & 0.011 & 0.285 & 0.244 & 0.049 & 0.049 \\
\hline
\end{tabular}

Regarding cluster thermal regime, in the first two weeks after veraison, berry temperature reached higher maximum values in $\mathrm{NC}$ and ED (Fig. 3). From the third week after veraison onward, maximum temperature was closer among treatments. In the inner canopy layers, the lowest values were recorded in $\mathrm{LD}$, followed by $\mathrm{IC}$, in the last week of ripening. Higher duration of elevated temperatures (HT35) was observed in the west side clusters of $\mathrm{NC}$ and ED plants. The lowest and the highest HT35 were achieved in east-side IC and west-side NC berries, respectively. However, the effect of irrigation treatments on HT35 was not statistically significant: however, main effect of the cluster location factor were shown. HT35 increased sharply from 2 to 3 weeks after veraison, with a similar trend in all treatments (Fig.3). After 3 weeks post-veraison, HT35 decreased markedly, and, at this time, the differences among treatments were also attenuated. During the first two weeks after veraison, IC and LD berries presented higher weight, $\mathrm{pH}$ and malic acid. Yet, significant differences concerning acids in berry juice, TSS and sugar per berry were not observed in the following ripening controls. Only $\mathrm{pH}$ was higher in IC berries until 6 weeks after veraison. At harvest, no significant differences among treatments were observed (Table 1). During the first three weeks after veraison, total phenols per berry were higher in $\mathrm{NC}$ but did not differ statistically in ED, LD and IC.
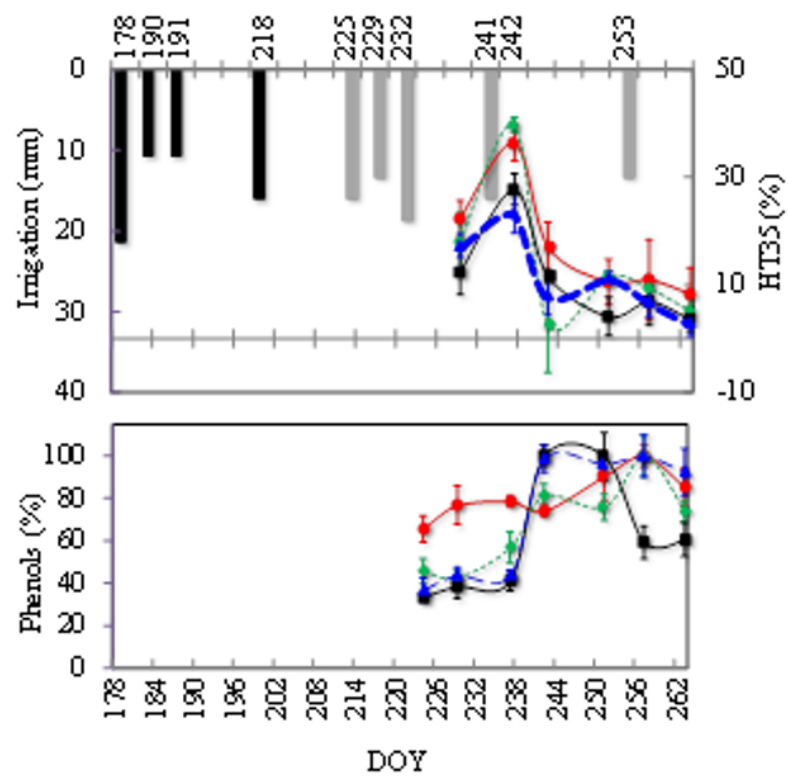

Fig.3. Irrigation supplied in pre $(\square$ and post-veraison ( ); variation HT35 (\%) in the timeframes between ripening controls and berry phenols (\% of maximum content) among treatments $(\bigcirc \mathrm{NC}, \triangle \mathrm{ED}, \boldsymbol{\square} \mathrm{IC}$ and $\boldsymbol{\Delta} \mathrm{LD})$. Mean $(\mathrm{n}=6) \pm \mathrm{SE}$.

By mid-ripening, higher phenol accumulation was observed in IC and LD. Thereafter, phenols decreased in IC, while in LD, ED and $\mathrm{NC}$ they continued to accumulate in berry skin until one week before harvest: significantly higher concentration in LD at harvest was observed. The small differences in normal heat hours among treatments did not induce significant differences in TSS/TA (Fig.4).

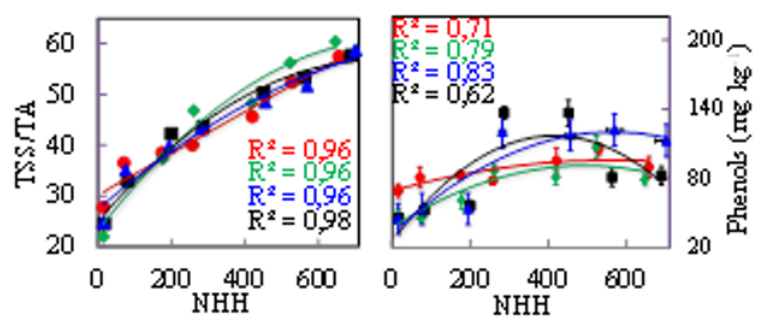

Fig.4. Relationships between TSS/TA, phenols and NHH in the treatments $(\triangle N C, \triangle E D, \boldsymbol{I C}$ and $\boldsymbol{\Delta} \mathrm{LD})$. Mean $(\mathrm{n}=12) \pm$ SE.

Yet, the thermal time, computed in normal heat hours, correlated well with phenol accumulation in NC, ED and LD but fitted less with IC phenols.

\subsection{Interactions among canopy coverage, duration of elevated temperatures and phenol accumulation}

Principal component analysis on total leaf area, HT35 and berry skin phenol content, from 4 weeks after veraison until harvest, separated treatments according to 2 components, explaining $74.8 \%$ of total variance (Fig.5). PC1 explained $44.8 \%$ of variation and discriminated HT35, phenols in NC and leaf area in IC. The variance of canopy coverage in $\mathrm{NC}$ and $\mathrm{ED}$, as well as phenols in IC and ED, were rather explained by PC2. For LD phenols, the correlation with PC2 was of low magnitude and LA_LD variance was explained both by PC1 and PC2.

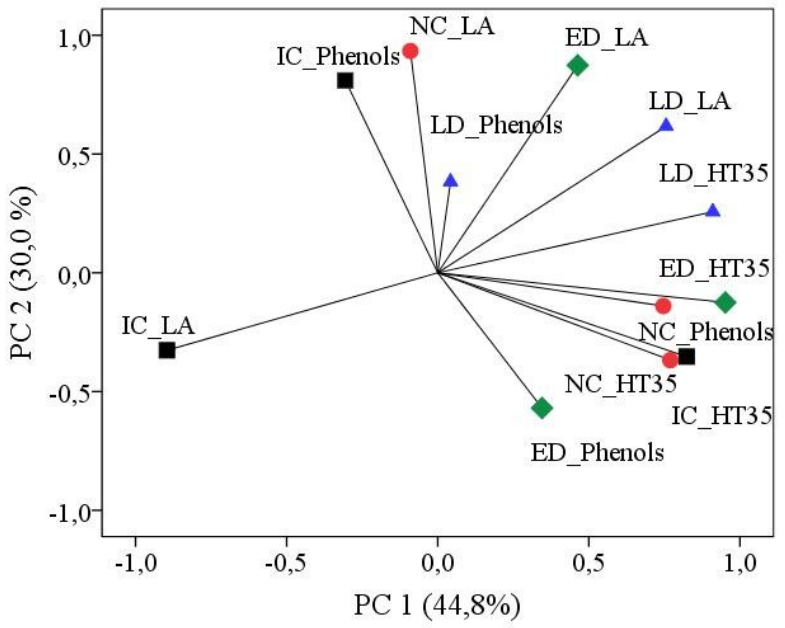

Fig.5. PCA of LA, berry phenols and HT35 from 4 WAV until harvest in the four treatments $(n=12)$. Different colours represent different treatments $(\mathrm{NC}, \triangleleft \mathrm{ED}, \boldsymbol{\square} \mathrm{IC}$ and $\boldsymbol{\Delta} \mathrm{LD})$.

\section{Discussion}




\subsection{Physiological performance and productivity}

Stem water potential and leaf gas exchange indicated anisohydric behaviour, good capacity to recover, and high physiological performances of Vermentino after severe water deficit $[16,17]$. Stomatal conductance was more sensitive to water stress than net assimilation. The vines were still able to reach the maximum net assimilation when subjected to moderate deficit, even though both ED and NC plants had been exposed to severe water stress. This result indicates that, under moderate water deficit, Vermentino is able to maintain high carbon assimilation rate and reach higher intrinsic water use efficiency. Water deficit reduced leaf area growth in deficit and non irrigated plants. Irrigation treatments induced higher vegetative growth and yield compared to non-irrigated control but did not change shoot weight significantly. However, we denote that, in this type of experiment, further years of trial can help better explain plant growth-yield responses. We showed that Vermentino is able to maintain high photosynthetic performance and water use efficiency under moderate water stress. Furthermore, by monitoring stem water potential and stomatal conductance or a micrometeorological variable that is responsive to both plant water status and stomatal conductance, like canopy or leaf temperature, it is possible to adapt and, hence, fine-tune an efficient irrigation for a given variety, under given vine growing environments. A substantial amount of water can be conserved by reducing irrigation supply compared to ETc, imposing mild to moderate water stress [11] during berry development.

\subsection{Cluster microclimate and berry quality}

The irrigation treatments promoted differences in light and thermal microclimate. PAR profiles measured at the fruit zone allowed evaluation of the shade effect of the upper canopy layers on the clusters, and indicated thinner NC and ED canopies compared to IC and LD plants and a significantly higher light exposure of the external clusters in NC and ED. By 5 weeks after veraison, the increments in HT35 were very small in all treatments, explaining the absence of significant differences in berry fresh weight at harvest. The lower berry size of ED in the first two weeks after veraison was a result of water deficit being set at berry growth stages $[2,7]$. Malic acid retention effect of the denser canopies and tartaric acid dilution of larger berries were observed in the more irrigated treatment in the first ripening stages. Regarding phenol accumulation, the higher content in LD berries can be ascribed to a more favourable light and thermal microclimate effect on phenylpropanoid metabolism $[18,19]$. Phenolic content in NC berries was affected by HT35 and limited source organ potential [8], due to lower leaf area. HT35 and thermal time influenced phenolics mainly in $\mathrm{NC}$, somewhat in ED and IC until mid-ripening, had little influence thereafter, and did not significantly affect LD phenols. Higher canopy coverage of IC and LD plants better balanced source-sink relations and had a positive effect on berry phenols, the accumulation peak being observed at the same phenological stage reported by other authors $[4,8]$. Lower HT35 had a slight positive effect on phenolics. Higher sunlight levels in LD clusters compared to IC promoted phenolic accumulation from mid-ripening onward. The combined effects of higher light levels in LD as compared to IC fruits and slightly lower exposure to elevated temperatures during the first weeks after veraison as compared to $\mathrm{NC}$ and $\mathrm{ED}$ plants $[4,5,18,19]$ determined the differences observed at harvest.

\section{Conclusions}

This work provides useful indications for guiding irrigation in Vermentino grapevines in arid and hot environments. The use of stem water potential or a micrometeorological parameter, quick water stressresponsive, namely canopy or leaf temperature, as a tool for scheduling vineyard irrigation can help to manage drip irrigation in order to save water, avoid excessive vigour and favour canopy and cluster microclimate during berry development stages. Weekly monitoring of stem water potential and stomatal conductance gave a warning signal of plant water status and evaporative demand and allowed for evaluating varietal responses to water stress.

The results of our study showed that water deficit induced lower leaf area and limited the potential berry phenolic accumulation in non-irrigated vines. High duration of elevated temperatures may reduce phenolic accumulation, but high levels of sunlight interception at the fruiting zone, particularly during mid-ripening, represent a major factor in promoting higher phenolic content in white berry skin. Under Mediterranean environments with high insolation during the growing season, negative impacts of limited soil water on grapevine source-sink balance and elevated temperatures during the first stages of ripening on berry composition may be reduced by applying pre-veraison deficit irrigation and imposing late water stress. Such irrigation strategies can improve the quality of white grapes by inducing a better light and thermal microclimate and favouring good berry sugar/acidy balance and high phenolic content at harvest.

The authors thank the Finetti farm and Dr. Renzo Peretto, Dr. Giovanni Ligios, Dr. Giampaolo Usai, and Dr. Nicola Tedde.

\section{References}

1. J. Flexas, J. Galmés, A. Gallé, J. Gulías, A. Pou, M. Ribas-Carbo, M. Tomàs, H. Medrano, Aust. J. Grape Wine Res. 16, 106-121 (2010)

2. M. Keller, R.P. Smithyman, L.J. Mills, Am. J. Enol. Vitic. 59, 221-234 (2008)

3. G. Roby, J.F. Harbertson, D.A. Adams, M.A. Matthews, Aust. J. Grape Wine Res. 10, 100-107 (2004)

4. L.G. Deluc, D.R. Quilici, A. Decendit, J. Grimplet, M.D. Wheatley, K.A. Schlauch, J.M. Merillon, J.C. 
Cushman, G.R. Cramer, BMC Genom. 10, 212 (2009)

5. A. Fernandes de Oliveira, M.G. Mameli, L. De Pau, D. Satta, G. Nieddu, S. Afr, J. Enol. Vitic. 34, 170183 (2013)

6. A. Fernandes de Oliveira, G. Nieddu, S. Afr, J. Enol. Vitic. 34,184-195 (2013)

7. T. Santos, C. Lopes, M.L. Rodrigues, C.R. Souza, J.R. Silva J. Maroco, J.S. Pereira, M.M. Chaves, Vitis 44, 117-125 (2005)

8. J.T. Matus, R. Loyola, A. Vega, A. Peña-Neira, E. Bordeu, P. Arce-Johnson, J.A. Alcalde, J. Exp. Bot. 60, 853-867 2009)

9. S. Poni, M. Gatti, A. Palliotti, Z. Dai, E. Duchêne, T-T. Truong, G. Ferrara, A.M.S. Matarrese, A. Gallotta, A. Bellincontro, F. Mencarelli, S. Tombesi, Sci. Hortic. 234, 445-462 (2018)

10. P.A. Myburgh, S. Afr. J. Enol. Vitic. 32, 89-103 (2011)

11. ARPAS. Analisi agrometeorologica e climatologica della Sardegna. Sassari, Italia (2013)

12. C.M. Lopes, P.A. Pinto, Vitis 44, 55-61 (2005)

13. G. Cola, L. Mariani, S. Parisi, O. Failla. Acta Italus Hortus 3, 31-34 (2012)

14. OIV. Recueil des méthodes internationales d'analyse des vins et des moûts, Paris (1990).

15. R. Di Stefano, M.C. Cravero, Riv. Vitic. Enol. 49, 37-45 (1991)

16. H.R. Schultz, Plant, Cell \& Envir. 26, 1393-1405 (2003)

17. M. Permanhani, J.M. Costa, M.A.F. Conceição, R.T. Souza, M.A.S Vasconcellos, M.M. Chaves, Theor. Exp. Plant Physiol. 28, 85-108 (2016)

18. A. Fernandes de Oliveira, G. Nieddu, Aust. J. Grape Wine Res. 22, 105-115 (2016)

19. A. Teixeira, J. Eiras-Dias, S.D. Castellarin, H. Gerós, Int. J. Mol. Sci. 14, 18711-18739 (2013) 